\title{
Psychometric properties of the Greek version of the NEI-VFQ 25
} Georgios Labiris*1,2, Andreas Katsanos' ${ }^{1}$, Michael Fanariotis ${ }^{2}$, Theodora Tsirouki ${ }^{1}$, Maria Pefkianaki ${ }^{1}$, Dimitrios Chatzoulis ${ }^{1}$ and Evangelia Tsironi ${ }^{1}$

Address: ${ }^{1}$ Ophthalmology Clinic, University of Thessaly, Larissa, Greece and ${ }^{2}$ Intermedico Network, Athens, Greece

Email: Georgios Labiris* - labiris@usa.net; Andreas Katsanos - andreakatbp@hotmail.com; Michael Fanariotis - m_fanariotis@intermedico.org; Theodora Tsirouki - tsirouki_theodora@yahoo.gr; Maria Pefkianaki - pefkianaki@hotmail.com; Dimitrios Chatzoulis - dchatzoulis@hotmail.com; Evangelia Tsironi - evangelia_tsironi@yahoo.gr

* Corresponding author

Published: 6 March 2008

BMC Ophthalmology 2008, 8:4 doi:I0.1 I86/I47|-24I5-8-4

This article is available from: http://www.biomedcentral.com/I47I-24I5/8/4

(C) 2008 Labiris et al; licensee BioMed Central Ltd.

This is an Open Access article distributed under the terms of the Creative Commons Attribution License (http://creativecommons.org/licenses/by/2.0), which permits unrestricted use, distribution, and reproduction in any medium, provided the original work is properly cited.

\begin{abstract}
Background: To evaluate the reliability and construct validity of a Greek version of the NEI-VFQ-25 in patients with chronic ophthalmic diseases.

Methods: We developed the Greek version of the instrument using forward and backward translation. One hundred-eighty-six patients responded to the questionnaire. To examine reliability, Cronbach's alpha for each subscale was used as an index of internal consistency. Test-retest reliability was evaluated with intraclass correlation coefficients. Regarding construct validity, both convergent and discriminant validities were calculated by means of multi-trait analysis. Rasch analysis was used to estimate the visual ability required by each item for a particular response, and each patient's visual ability. Correspondingly, instrument validity was evaluated by estimating the distribution of residuals for item and subject measures.
\end{abstract}

Results: Four patient groups were studied, each including participants with a single cause of visual impairment. Group I consisted of 84 glaucoma subjects. Group 2 included 30 subjects with age-related macular degeneration (ARMD); group 3 included 25 subjects with dry-eye syndrome, whereas group 4 included 18 cataract patients. Twenty-nine healthy individuals comprised the control group. NEI-VFQ scores (mean \pm SD) for the glaucoma, ARMD, dry-eye, cataract and control groups were: $76.9 \pm 20.2,70.9 \pm 20.2,81.6 \pm 16.5,73.5 \pm 24.0$ and $93.7 \pm$ 8.9 respectively. Item analysis revealed no significant data skewing. Cronbach's alpha ranged from 0.678 to 0.926 , with most subscales having high internal consistency. Intraclass correlation coefficient ranged from 0.717 to 0.910 for all subscales. All items passed the convergent and discriminant validity tests. Strong correlations were detected between visual acuity and "general vision", "distant activities" and "near activities" subscales. Significant correlations were also detected between visual field deficits and the "peripheral vision" and "general vision" subscales. Rasch analysis revealed potential weaknesses of the instrument that are associated with the assumptions of the model itself. Specifically, low precision of the "agreement" items was detected in the estimation of visual ability. Twenty-three percent of the subjects had fit statistics that fell outside the tolerance box.

Conclusion: Although traditional validation methods indicated that the Greek version of the NEI-VFQ-25 is a valid and reliable instrument for VS-QoL assessment, Rasch analysis detected significant misfits to the model, especially of the "agreement" items. This means that results of the corresponding subscales should be interpreted with extreme caution. 


\section{Background}

The impact of ophthalmic diseases on quality of life (QoL) has been documented in a series of studies [1-4]. Numerous instruments have been developed: general, vision-specific, or disease specific ones (i.e. glaucoma-specific QoL instruments) that evaluate patients' subjective perceptions regarding QoL [5-8]. In the majority of QoL studies, an association is attempted between objective clinical indices that quantify functional status and a series of quality dimensions that purportedly reflect QoL. However, vision-specific QoL (VS-QoL) studies in Greek populations are fragmented. In fact, apart from the prevalent general QoL questionnaires, none of the vision-specific or ophthalmic-disease-specific instruments has been validated in Greek populations [9].

The NEI-VFQ 25 (National Eye Institute visual function questionnaire) is a widely used vision-specific instrument for the assessment of VS-QoL. The instrument was originally developed by the National Eye Institute mainly for the English-speaking North American populations [10]. NEI-VFQ 25 is a short form of the original 51-item version [11]. Reliability and validity of the English version of the NEI-VFQ 25 have been evaluated and found comparable to the 51-item version. NEI-VFQ 25 measures the following vision-depended functions: General health, general vision, ocular pain, near activities, distant activities, social functioning, mental health, role difficulties, dependency, driving, color vision and peripheral vision. A 0-100 point scale is used for subscale scores. A score of 100 indicates the best possible score, while 0 indicates the worse possible score. With slight modifications, the original NEI-VFQ 25 has been translated and validated for other populations as well [12-15]. The original NEI-VFQ 25 has been used as an index of VS-QoL for a series of diseases that exert variable impact on visual functional capacity, including glaucoma [16], age-related macular degeneration [17], diabetic eye disease [18], dry eye syndrome [19], blepharospasm [20], and retinitis pigmentosa [21]. Moreover, the instrument has been used as an index of the impact of therapeutic interventions and rehabilitation programs on VS-QoL [22-24].

The aim of our study was the evaluation of the reliability and validity of NEI-VFQ 25 in a sample of native Greek subjects with a series of common ophthalmic diseases.

\section{Methods}

\section{Instrument development}

The study adhered to the tenets of the Declaration of Helsinki and approval was granted by the Bioethics Committee of the University of Thessaly. All participants provided written informed consent.
For this study we developed a Greek version of the NEIVFQ 25. The original NEI-VFQ 25 is a VS-QoL instrument that has been used in numerous studies. The concepts investigated by the items have been extensively analyzed both during the development of the original version and during the validation of the instrument in other languages. Forward translation was done by native Greek ophthalmologists with solid command of the English language. Two independent bilingual speakers performed the backward translation. Proper adaptation of the questionnaire to the experience of Greek patients mandated slight modification of three questions. Thus, item "13" [How much difficulty do you have visiting people at their homes, at parties, or in restaurants?] was translated as: [How much difficulty do you have visiting people at their homes or outdoors, to restaurants, cafes, or in church?]. Accordingly, item "A7" [Because of your eyesight, how much difficulty do you have taking part in active sports or other outdoor activities that you enjoy (like golf, bowling, jogging, or walking)?] was translated as: [Because of your eyesight, how much difficulty do you have taking part in active sports or other outdoor activities that you enjoy (going long walks or jogging)?]. On the other hand, item "9" [Because of your eyesight, how much difficulty do you have going down steps, stairs, or curbs in dim light or at night?] was modified as follows: [Because of your eyesight, how much difficulty do you have going down stairs, or curbs in dim light or at night?], since the Greek words for "stairs" and "steps" are almost identical. The Greek version of the instrument was pilot-tested in a sample of ten ophthalmic patients who visited the outpatient service of our clinic for their annual check-up. The results of the pilot-testing indicated that the instrument was well accepted, since it was short in duration (about $10 \mathrm{~min}$ utes) and all items were easy to understand.

It should be mentioned that the NEI-VFQ 25 has already been translated into Greek (Laboratory of Experimental Ophthalmology of Aristotle University, Thessaloniki, Greece, 2000) [25]. However, to our knowledge, it has not been validated in native populations. In addition to the aforementioned modifications required by the proper adaptation of the instrument in Greek language, a series of minor differences in the expression of the items suggested a thorough revision of the translation process. Nevertheless, our translation of the NEI-VFQ 25 was almost identical to the one produced by the Laboratory of Experimental Ophthalmology of the Aristotle University.

\section{Study Design}

Evaluation of the reliability and validity of the Greek version of the NEI-VFQ 25 questionnaire was conducted by the University Eye clinic, Larissa, Greece, between August and November 2006. The University Hospital of Larissa is an 800-bed General Hospital, located at the center of 
mainland Greece, offering tertiary healthcare to more than one million beneficiaries. The University Eye Clinic provides integrated ophthalmic services to patients from four counties in mainland Greece and one on the islands. Two hundred fifty patients were recruited for the study. Of them, 186 successfully responded to the questionnaire, including the test-retest module (response rate: 74.4\%). The patients were randomly selected from the local national health system hospitals of the corresponding counties.

\section{Subject groups}

Subject group 1 consisted of a random sample of 84 known glaucoma patients ( 38 males/ 46 females). All subjects had been diagnosed with primary open angle glaucoma (POAG), pseudoexfoliation glaucoma (PXG), pigment glaucoma (PG) or normal tension glaucoma (NTG) at least two years prior to the study, and demonstrated adequate compliance. Glaucoma patients had bilateral typical glaucomatous visual field defects on Humphrey 24-2 tests, untreated intraocular pressure higher than $22 \mathrm{mmHg}$ (except for the NTG patients) and either retinal nerve fibre layer defects compatible with glaucoma on OCT, or optic nerve heads with a typical glaucomatous appearance. Subject group 2 consisted of a random sample of 30 age-related macular degeneration (ARMD) patients (14 males/16 females). To be eligible for the ARMD group, each subject should have variable bilateral involvement presenting either with geographic atrophy involving the fovea, choroidal neovascular membrane, or pigment epithelium defects. Subject group 3 consisted of a random sample of 25 patients ( 1 male/ 24 females) diagnosed with dry-eye syndrome. These had been diagnosed according to the European classification criteria [26] and presented Schirmer score $<5 \mathrm{~mm}$ at 5 minutes with abnormal Ocular Surface Discomfort Index scores. Subject group 4 consisted of a random sample of 18 cataract patients ( 5 males/13 females). Cataract subjects were recruited from the waiting lists for cataract extraction. Among the eligibility criteria for all subjects was the necessity for a single reason of visual impairment that classified them accordingly to the abovementioned groups. Subsequently, patients presenting more than one causes of visual impairment (e.g. POAG and ARMD) were excluded. Subjects with serious mental and/or major systemic diseases were also excluded. The control group consisted of a random sample of 29 adults ( 6 males/23 females) who visited the outpatient office for their annual ophthalmic checkup and had no apparent cause of visual impairment.

\section{Data collection}

Subjects responded to the self-administered Greek version of the NEI-VFQ 25 in the presence of an independent researcher who had no direct involvement in the provi- sion of care. All questionnaires were completed prior to the clinical examination. Clinical and demographic data regarding the participants was retrieved from their medical records. Proxy responses (i.e. from family members) were excluded.

\section{Descriptive analysis and item analysis}

Data from the different subject groups were used for the item analysis. Missing values were estimated for each item. Large ceiling or floor effects were evaluated as well.

\section{Reliability}

Reliability analysis was done by Cronbach's alpha estimation as an index of internal consistency for each subscale [27]. A time window of three weeks between two consecutive surveys ( $20 \pm 5$ days) was used for the assessment of test-retest reliability. Quantification of test-retest reliability was done using intraclass correlation coefficients.

\section{Construct validity}

Construct validity was evaluated by means of multi-trait analysis according to Campbell and Fiske [28]. It is known that convergent and discriminant validities are subtypes of construct validity. According to the multitrait-multimethod matrix, convergent validity is the degree to which concepts that should be related theoretically are interrelated in reality, while discriminant validity is the degree to which concepts that should not be related theoretically, are in fact not interrelated in reality. In brief, each item was hypothesized to belong to only one multi-item subscale and correlations between the score on that item and the scores on all the subscales were computed. Then, for each item, if the correlation between the score on that item and the score on the subscale to which that item belongs is 0.4 or higher, that item is validated in terms of convergent validity. On the other hand, each item was validated for discriminant validity if the correlation between the score of the item and the score on the subscale where it belongs is greater than all the correlations among the score of the item and the remaining subscales.

\section{Rasch analysis}

Besides the traditional methods, the psychometric properties of the Greek NEI-VFQ 25 were also evaluated by Rasch analysis. The item response theory has been described in earlier studies $[29,30]$. Rasch models have been used in the validation of a series of vision-specific and diseasespecific QoL instruments [31,32] as well as the assessment of therapeutic interventions on QoL [33]. In brief, item response models attempt to estimate the values of latent variables on an interval scale from item scores that form an ordinal scale. "Visual ability" is the variable of interest regarding the assessment of visual function by means of the item response theory. Each patient is supposed to have a unique visual ability that determines the difficulty in 
performing certain daily tasks. In fact, each activity requires a certain visual capacity in order to be performed with ease.

The tests of construct validity measure the fit of the person measures to the model, and the correlations of personand item parameter values with other variables, compared with expected correlations. The tests of content validity measure the fit of individual items to the model, the estimation errors of item parameter values, and the spacing and range of item parameter values, relative to the distribution of person parameter values.

\section{Statistical analysis}

Statistical analyses were performed with SPSS ${ }^{\circledast}$ version 13 for Windows (SPSS Inc, Chicago, IL). Rasch analysis was performed with the Winsteps programme (Linacre, 2007).

\section{Results}

Regarding glaucoma subjects, 43 patients had primary open angle glaucoma (POAG), 10 had pseudoexfoliation glaucoma (PXG), 16 had normal tension glaucoma (NTG) and 15 subjects had ocular hypertension (OH). The MD ranged from -1.9 dB to -7.1 dB in Humphrey 242 threshold testing (mean: $-3.2 \mathrm{~dB}$ ). Regarding ARMD subjects, 28 patients presented variable degrees of bilateral geographical atrophy, while 2 patients presented exudative changes in one eye. Regarding cataract subjects, mean LOCS III score for nuclear opalescence was 3.1 and LOCS III score for nuclear color was 3.3. Regarding the dry-eye syndrome group, all subjects were treated with artificial tears, 13 subjects reported that artificial tears treatment was effective, while 17 subjects demonstrated combined fluorescein score $>0.5$. Demographics and clinical data for the participants are presented in Table 1.

Mean subscale and overall NEI-VFQ scores for the different groups of subjects are presented in Table 2. Mean NEIVFQ scores ranged from $81.6 \pm 16.5$ for the dry-eye patient group to $70.9 \pm 20.2$ for the ARMD group. Control subjects presented mean overall NEI-VFQ score of $93.7 \pm 8.9$.
Item analysis is presented in Table 3. The highest missing values were identified in the questions regarding "Driving" (missing percentages of $13.4 \%$ and $68.2 \%$ in items 15 and 16 respectively). On the other hand, significantly lower missing percentages were identified in the remaining items with higher values $(7.6 \%)$ both in item 22 ("Have less control because of poor eyesight") and item 23 ("Rely on others because of poor eyesight"). Ceiling and floor values of the sample suggested that the data was not strongly skewed.

Evaluation of the reliability of the Greek version of the NEI-VFQ 25 is presented in Table 4. Cronbach's alpha ranged from 0.678 for the "Vision-specific social functioning" subscale to 0.926 for the "Vision specific role difficulties". Nevertheless, the majority of the subscales presented high internal consistency. Regarding test-retest reliability, intraclass correlation coefficient was higher than 0.7 in all subscales; it ranged from 0.717 for the "Color vision" to 0.910 for the "Vision-specific social functioning".

Evaluation of the validity of the Greek version of NEI-VFQ 25 is presented in the multitrait-multimethod matrix (see Additional file 1) and Table 4. All items passed the convergent and discriminant validity tests.

The impact of visual acuity and visual field deficits on vision-specific quality of life is presented in Table 5 . Strong Pearson correlations were detected between BCVA and the corresponding subscales that are associated with central vision (i.e. general vision and near activities). Correspondingly, strong Pearson correlations were detected between VF scores and "peripheral vision" and "general vision subscales".

Regarding Rasch analysis, the normalized item fit statistics are presented in Table 6 . The expected values are 0 , with a tolerance of \pm 2 deviation units. Positive values indicate that response residuals exceed expectations of the model, whereas negative values indicate that response residuals are less than the expectations of the model. Figure 1 illustrates the infit and outfit values for the list of items. Six items fell outside the tolerance box. The most misfitting

Table I: Demographics and clinical data

\begin{tabular}{|c|c|c|c|c|c|}
\hline & Glaucoma & ARMD & Cataract & Dry Eye & Control \\
\hline Mean \pm SD age (years) & $60.9 \pm 11.7$ & $65 \pm 4.4$ & $63 \pm 7.3$ & $59.1 \pm 8.7$ & $56 \pm 8.9$ \\
\hline males/females & $38 / 46$ & $14 / 16$ & $5 / 13$ & $1 / 24$ & $6 / 23$ \\
\hline mean BCVA best (range) & $0.63(0.5$ to 0.8$)$ & $0.4(0.67$ to 0.32$)$ & $0.5(0.63$ to 0.32$)$ & $0.8(0.67$ to 1.0$)$ & I \\
\hline mean BCVA worse (range) & $0.4(0.33$ to 0.63$)$ & $0.33(0.25$ to 0.40$)$ & $0.29(0.16$ to 0.4$)$ & $0.67(0.5$ to 0.8$)$ & 0.8 (I to 0.67$)$ \\
\hline VF MD (dB) (range) & $-3.2(-7.1$ to- 1.9$)$ & - & - & - & - \\
\hline 0 medical comorbitities & 8 & 4 & 6 & 4 & 13 \\
\hline I medical comorbitities & 47 & 8 & 5 & 15 & 8 \\
\hline$\geq \mathbf{2}$ medical comorbitities & 29 & 18 & 7 & 6 & 8 \\
\hline
\end{tabular}


Table 2: Index and subscale scores

\begin{tabular}{|c|c|c|c|c|c|c|c|c|c|c|}
\hline \multirow{3}{*}{ NEI-VFQ 25 subscales } & \multicolumn{10}{|c|}{ Subject Group } \\
\hline & \multicolumn{2}{|c|}{ Glaucoma } & \multicolumn{2}{|c|}{ ARMD } & \multicolumn{2}{|c|}{ Dry-eye } & \multicolumn{2}{|c|}{ Cataract } & \multicolumn{2}{|c|}{ Control } \\
\hline & Mean & SD & Mean & SD & Mean & $\mathrm{SD}$ & Mean & SD & Mean & SD \\
\hline General health & 55.3 & 20.3 & 57.6 & 17.1 & 45.9 & 17.2 & 57.8 & 19.7 & 80.3 & 12.2 \\
\hline General vision & 69.6 & 15.5 & 56.6 & 10.9 & 75.1 & 15.2 & 60 & 17.4 & 90.7 & 12.9 \\
\hline Ocular pain & 69.9 & 23.1 & 94.2 & 16 & 60.5 & 18.9 & 84 & 20.5 & 89.7 & 12.1 \\
\hline Near activities & 78.7 & 18.7 & 58.6 & 23 & 86.2 & 16.3 & 65.6 & 26.9 & 96.1 & 9.7 \\
\hline Distance activities & 82.2 & 19 & 74.4 & 17.7 & 90.2 & 13.9 & 74.7 & 18.5 & 96 & 7 \\
\hline Vision specific social functioning & 89.2 & 19.4 & 89.1 & 12.8 & 94.1 & 9.7 & 84.3 & 22.9 & 99.4 & 3.1 \\
\hline Vision specific mental health & 69.7 & 21.6 & 63.3 & 22.4 & 80.8 & 19.3 & 67.8 & 24.5 & 89.7 & 10.4 \\
\hline Vision specific role difficulties & 74.3 & 21.7 & 59.8 & 24.4 & 86.5 & 18.7 & 68 & 29.3 & 94.8 & 12.1 \\
\hline Vision specific dependency & 82.5 & 25.1 & 70.3 & 22.5 & 91.3 & 19.8 & 79.6 & 26.4 & 97.7 & 7 \\
\hline Driving & 81.1 & 16.9 & 61.1 & 26.4 & 90 & 11.5 & 75 & 35.4 & 93.8 & 8 \\
\hline Color vision & 88.3 & 19 & 86.7 & 23.4 & 89.3 & 22.1 & 86.1 & 17.6 & 100 & 0 \\
\hline Peripheral vision & 82.4 & 21.4 & 79.2 & 25.5 & 89.6 & 15.4 & 79.4 & 28.3 & 95.7 & 11.7 \\
\hline Overall Score & 76.9 & 20.2 & 70.9 & 20.2 & 81.6 & 16.5 & 73.5 & 24 & 93.7 & 8.9 \\
\hline
\end{tabular}

items were the "overall eyesight" and the "overall health". In accordance with other researchers, gross misfits to the model were detected by the items that used agreement instead of difficulty rating scales. However, when the "agreement" items were removed from the model (table
7), the number of misfits decreased significantly (Figure 2).

Figure 3 illustrates the distribution of visual ability measures. Higher values indicate greater visual ability and less disability. On the other hand, lower values indicate lower

Table 3: Item analysis

\begin{tabular}{|c|c|c|c|c|c|c|}
\hline \multirow[t]{2}{*}{ Item } & \multicolumn{2}{|c|}{ Missing responses } & \multicolumn{2}{|c|}{ Floor responses } & \multicolumn{2}{|c|}{ Ceiling responses } \\
\hline & Number & $\%$ & Number & $\%$ & Number & $\%$ \\
\hline I. General Health: 5-level health rating & I & 0.5 & 14 & 8.9 & 6 & 3.8 \\
\hline 2. General Vision: 6-level general vision & 1 & 0.5 & 1 & 0.6 & 6 & 3.8 \\
\hline 3. Mental Health: Amount true: worry & 2 & 1.3 & 21 & 13.4 & 11 & 7.0 \\
\hline 4. Ocular Pain: Amount pain & 2 & 1.3 & 1 & 0.6 & 55 & 35.0 \\
\hline 5. Near Vision: Reading normal newsprint & 4 & 2.5 & 21 & 13.4 & 38 & 24.2 \\
\hline 6. Near Vision: See well up-close & 1 & 0.5 & I & 0.6 & 46 & 29.3 \\
\hline 7. Near Vision: Finding objects on crowded shelf & 1 & 0.5 & 5 & 3.2 & 88 & 56.1 \\
\hline 8. Distance Vision: Reading street signs & 2 & 1.3 & 6 & 3.8 & 64 & 40.8 \\
\hline 9. Distance Vision: Going down stairs at night & 2 & 1.3 & 2 & 1.3 & 61 & 38.9 \\
\hline 10. Peripheral Vision: Seeing objects off to side & 2 & 1.3 & I & 0.6 & 82 & 52.2 \\
\hline I I. Social Function: Seeing how people react & 2 & 1.3 & 2 & 1.3 & 99 & 63.1 \\
\hline 12. Color Vision: Difficulty matching clothes & i & 0.5 & I & 0.6 & 101 & 64.3 \\
\hline 13. Social Function: Visiting others & 1 & 0.5 & 4 & 2.5 & 114 & 72.6 \\
\hline 14. Distance Vision: Going out to movies/plays & 6 & 3.8 & 56 & 35.7 & 56 & 35.7 \\
\hline 15. Driving: Daylight familiar places & 21 & 13.4 & 84 & 53.5 & 52 & 33.1 \\
\hline 16. Driving: At night & 50 & 68.2 & 1 & 0.6 & 12 & 7.6 \\
\hline 17. Role Limitation: Accomplish less & 8 & 5.1 & 6 & 3.8 & 53 & 33.8 \\
\hline 18. Role Limitation: Limited in endurance & 10 & 6.4 & 6 & 3.8 & 53 & 33.8 \\
\hline 19. Ocular Pain: Amount time: pain & 8 & 5.1 & I & 0.6 & 73 & 46.5 \\
\hline 20. Dependency: Stay home most of time & 6 & 3.8 & 14 & 8.9 & 80 & 51.0 \\
\hline 2I. Mental Health: Amount true: frustrated & 9 & 5.7 & 11 & 7.0 & 76 & 48.4 \\
\hline 22. Mental Health: Amount true: no control & 12 & 7.6 & 6 & 3.8 & 84 & 53.5 \\
\hline 23. Dependency: Rely too much on other's word & 12 & 7.6 & 4 & 2.5 & 92 & 58.6 \\
\hline 24. Dependency: Need much help from others & 10 & 6.4 & 6 & 3.8 & 89 & 56.7 \\
\hline 25. Mental Health: Amount true: embarrassment & 9 & 5.7 & 8 & 5.1 & 100 & 63.7 \\
\hline
\end{tabular}


Table 4: Reliability and validity analysis

\begin{tabular}{|c|c|c|c|c|c|c|}
\hline Subscale & Number of items & $\begin{array}{l}\text { Intraclass } \\
\text { correlation } \\
\text { coefficients }\end{array}$ & Cronbach's alpha & $\begin{array}{l}\text { Range of item-scale } \\
\text { correlations }\end{array}$ & Convergent validity & $\begin{array}{l}\text { Discriminant } \\
\text { validity }\end{array}$ \\
\hline General Health & 1 & $0.84 I$ & NA & NA & NA & NA \\
\hline General Vision & 1 & 0.889 & NA & NA & NA & NA \\
\hline Ocular pain & 2 & 0.803 & 0.851 & $0.893-0.903$ & 100 & 100 \\
\hline Near activities & 3 & 0.901 & 0.734 & $0.719-0.875$ & 100 & 100 \\
\hline $\begin{array}{l}\text { Distance } \\
\text { activities }\end{array}$ & 3 & 0.908 & 0.686 & $0.752-0.892$ & 100 & 100 \\
\hline $\begin{array}{l}\text { Vision specific } \\
\text { social } \\
\text { functioning }\end{array}$ & 2 & 0.91 & 0.678 & $0.887-0.889$ & 100 & 100 \\
\hline $\begin{array}{l}\text { Vision specific } \\
\text { mental health }\end{array}$ & 4 & 0.823 & 0.786 & $0.596-0.837$ & 100 & 100 \\
\hline $\begin{array}{l}\text { Vision specific } \\
\text { role difficulties }\end{array}$ & 2 & 0.888 & 0.926 & $0.902-0.907$ & 100 & 100 \\
\hline $\begin{array}{l}\text { Vision specific } \\
\text { dependency }\end{array}$ & 3 & 0.826 & 0.848 & $0.835-0.899$ & 100 & 100 \\
\hline Driving & 3 & 0.871 & 0.757 & $0.575-0.953$ & 100 & 100 \\
\hline Color vision & 1 & 0.717 & NA & NA & NA & NA \\
\hline Peripheral vision & I & 0.84 & NA & NA & NA & NA \\
\hline
\end{tabular}

N.A.: Not applicable (needs two or more items).

Table 5: Pearson correlations of NEI VFQ 25 subscales with visual acuity and visual fields

\begin{tabular}{|c|c|c|c|c|c|}
\hline & & BCVA worse & BCVA better & VF worse & VF better \\
\hline \multirow[t]{2}{*}{ General Health } & Pearson Correlation & -0.145 & -0.078 & -0.175 & -0.145 \\
\hline & Sig. (2-tailed) & 0.231 & 0.521 & 0.153 & 0.238 \\
\hline \multirow[t]{2}{*}{ General Vision } & Pearson Correlation & $-0.279(*)$ & $-0.25 \mathrm{I}\left({ }^{*}\right)$ & $-0.444(* *)$ & $-0.407(* *)$ \\
\hline & Sig. (2-tailed) & 0.019 & 0.035 & 0 & 0.001 \\
\hline \multirow[t]{2}{*}{ Ocular Pain } & Pearson Correlation & -0.082 & -0.065 & -0.1 & -0.216 \\
\hline & Sig. (2-tailed) & 0.499 & 0.589 & 0.415 & 0.075 \\
\hline \multirow[t]{2}{*}{ Near Activities } & Pearson Correlation & $-0.331(* *)$ & $-0.337(* *)$ & $-0.36 I(* *)$ & $-0.4 I I(* *)$ \\
\hline & Sig. (2-tailed) & 0.005 & 0.004 & 0.002 & 0 \\
\hline \multirow[t]{2}{*}{ Distant Activities } & Pearson Correlation & $-0.440(* *)$ & -0.159 & $-0.260(*)$ & $-0.346(* *)$ \\
\hline & Sig. (2-tailed) & 0 & 0.186 & 0.031 & 0.004 \\
\hline \multirow[t]{2}{*}{ Social Functioning } & Pearson Correlation & -0.369 (**) $^{*}$ & -0.159 & -0.227 & $-0.295\left(^{*}\right)$ \\
\hline & Sig. (2-tailed) & 0.002 & 0.184 & 0.061 & 0.014 \\
\hline \multirow[t]{2}{*}{ Mental Health } & Pearson Correlation & $-0.236\left(^{*}\right)$ & -0.172 & -0.021 & -0.083 \\
\hline & Sig. (2-tailed) & 0.047 & 0.15 & 0.862 & 0.498 \\
\hline \multirow{2}{*}{ Role Difficulties } & Pearson Correlation & -0.218 & -0.199 & -0.204 & -0.242 \\
\hline & Sig. (2-tailed) & 0.074 & 0.103 & 0.1 & 0.05 \\
\hline \multirow[t]{3}{*}{ Dependency } & Pearson Correlation & $-0.475(* *)$ & -0.242 & -0.174 & $-0.292\left(^{*}\right)$ \\
\hline & Sig. (2-tailed) & 0 & 0.065 & 0.196 & 0.028 \\
\hline & $\mathrm{N}$ & 59 & 59 & 57 & 57 \\
\hline \multirow[t]{3}{*}{ Driving } & Pearson Correlation & -0.239 & -0.134 & $-0.37 I(*)$ & -0.041 \\
\hline & Sig. (2-tailed) & 0.187 & 0.466 & 0.04 & 0.826 \\
\hline & $N$ & 32 & 32 & 31 & 31 \\
\hline \multirow[t]{2}{*}{ Color vision } & Pearson Correlation & $-0.405(* *)$ & $-0.345(* *)$ & -0.231 & $-0.288(*)$ \\
\hline & Sig. (2-tailed) & 0.001 & 0.004 & 0.062 & 0.019 \\
\hline \multirow[t]{2}{*}{ Peripheral vision } & Pearson Correlation & -0.22 & -0.087 & $-0.334(* *)$ & $-0.336(* *)$ \\
\hline & Sig. (2-tailed) & 0.07 & 0.478 & 0.006 & 0.005 \\
\hline
\end{tabular}

**: Correlation is significant at the 0.01 level (2-tailed).

*: Correlation is significant at the 0.05 level (2-tailed). 
Table 6: Estimates of item measures and fit statistics from Rasch analysis

\begin{tabular}{|c|c|c|c|c|c|}
\hline Item & Item Number & $\rho$ & Standard Error & Infit zstd & Outfit zstd \\
\hline Matching clothes & 12 & -1.07 & 0.14 & 0.00 & -0.20 \\
\hline Finding something & 7 & -0.92 & 0.13 & 0.10 & -0.30 \\
\hline See reaction & 11 & -0.92 & 0.13 & 2.20 & 2.00 \\
\hline Visit people & 13 & -0.82 & 0.12 & -0.70 & -1.30 \\
\hline Noticing objects & 10 & -0.7 & 0.11 & -0.70 & -0.90 \\
\hline Eye pain & 4 & -0.42 & 0.10 & -2.30 & -3.00 \\
\hline Going down steps & 9 & -0.41 & 0.10 & -1.80 & -2.10 \\
\hline Reading signs & 8 & -0.4 & 0.10 & -0.20 & -0.50 \\
\hline See up close & 6 & -0.29 & 0.09 & 0.30 & -0.20 \\
\hline Overall eyesight & 2 & -0.1 & 0.09 & -6.90 & -6.60 \\
\hline Reading print & 5 & -0.03 & 0.09 & 2.70 & 2.60 \\
\hline Overall health & 1 & 0.15 & 0.08 & 5.80 & 5.40 \\
\hline Worry about eyesight & 3 & 0.2 & 0.09 & -1.20 & -0.90 \\
\hline See movies & 14 & 0.24 & 0.09 & 6.90 & 6.80 \\
\hline Limited & 18 & 0.32 & 0.09 & 1.30 & 1.60 \\
\hline Accomplish less & 17 & 0.32 & 0.09 & -0.40 & 0.30 \\
\hline Stay home & 20 & 0.44 & 0.09 & 1.10 & 1.40 \\
\hline Feel frustrated & 21 & 0.48 & 0.09 & 1.20 & 0.90 \\
\hline Less control & 22 & 0.69 & 0.10 & 0.00 & 0.40 \\
\hline Need help & 24 & 0.71 & 0.10 & -2.90 & -1.60 \\
\hline Eye discomfort & 19 & 0.72 & 0.10 & -0.70 & -0.10 \\
\hline Rely too much & 23 & 0.88 & 0.11 & 0.60 & 0.60 \\
\hline Embarrass myself & 25 & 0.94 & 0.11 & -0.60 & 0.00 \\
\hline
\end{tabular}

visual ability and suggest that the subject is more disabled. The distributions of the infit and outfit statistics for the estimates of visual ability are presented in Figure 4. Twenty six percent of the patients had fit statistics that fell outside the \pm 2 tolerance box.

\section{Discussion}

The primary objective of our study was the evaluation of the reliability and construct validity of the NEI-VFQ 25 in native Greek populations with a series of common ophthalmic diseases. Proper adaptation of the instrument to the Greek norms mandated slight modification of some items and a thorough revision of the translation process that had already been performed by previous investiga-

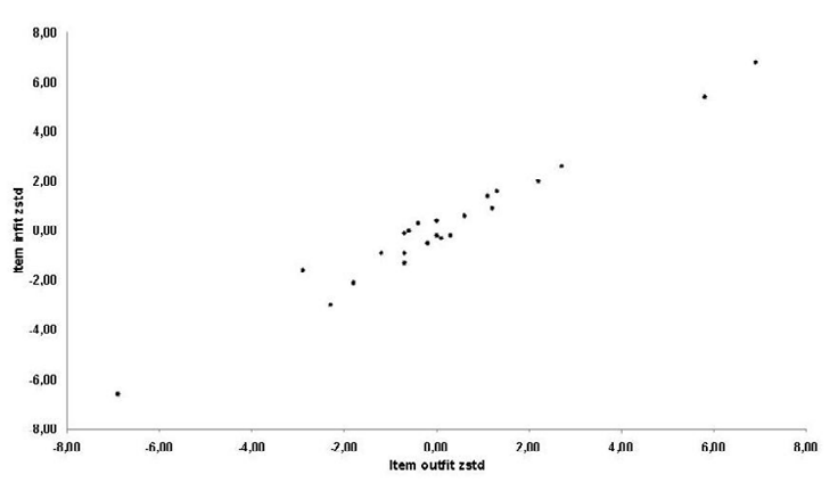

Figure I

Infit and outfit values for the list of items. tors. Minor modifications of some items were considered necessary during the translation and validation of the NEI-VFQ 25 in other populations, too $[12,13,15]$.

Contrary to the original validation studies in North American populations, relatively high missing rates were encountered in some subscales. However, these missing rates were comparably lower than the ones encountered during the translation and validation of the instrument in other populations [13]. In fact, except for the "Driving" subscale, no significant missing rates were found. Thus, contrary to what Suzukamo and collaborators did, in our study no substitution was performed between the regular

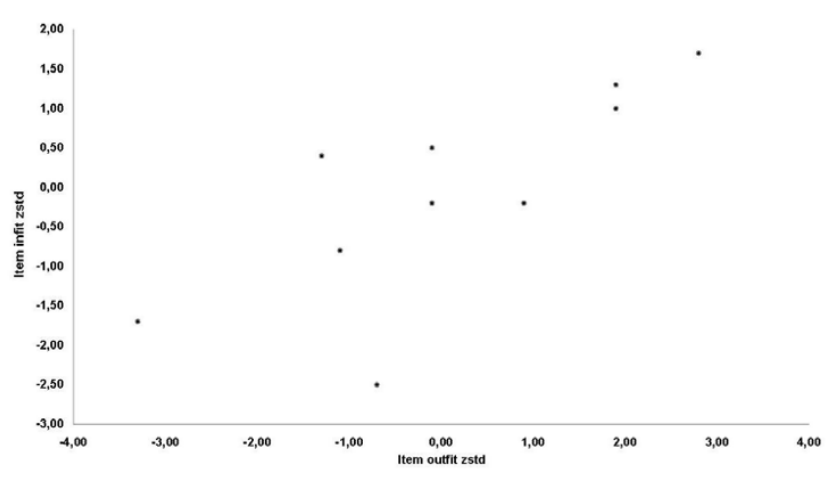

Figure 2

Infit and outfit values for the list of items - "agreement" items removed from model. 
Table 7: Estimates of item measures and fit statistics from Rasch analysis (difficulty items only)

\begin{tabular}{lrrrrr}
\hline Item & Item number & $\rho$ & Standard Error & Infit zstd & Outfit zstd \\
\hline Matching clothes & 12 & -0.77 & 0.16 & -0.70 \\
Finding something & 7 & -0.58 & 0.15 & -2.50 \\
See reaction & 11 & -0.58 & 0.15 & 1.90 \\
Visit people & 13 & -0.43 & 0.14 & -0.10 & -1.30 \\
Noticing objects & 10 & -0.27 & 0.13 & 0.50 \\
Going down steps & 9 & 0.16 & 0.12 & 0.40 \\
Reading signs & 8 & 0.18 & 0.12 & 2.80 \\
See up-close & 6 & 0.34 & 0.11 & -0.10 & 0.90 \\
Reading print & 5 & 0.74 & 0.11 & -1.00 \\
See movies & 14 & 1.2 & 0.11 & -0.20 \\
\hline
\end{tabular}

items with high missing rates and the corresponding optional ones with low missing rates within selected subscales [13]. On the other hand, high ceiling percentages were encountered in some items (i.e. "Social function: visiting others" and "Driving: driving at night"). However, no significant skewing of data was detected.

The subscales of the Greek version of NEI-VFQ 25 presented variable but adequate internal consistencies indicating high reliability of the instrument in the population studied. The lowest values of Cronbach's alpha were detected in "Social Functioning" (0.678) and "Distance Activities" (0.686) subscales, while the rest of the subscales presented significantly higher values. On the other hand, the time-window of three weeks between test and retest visits, ensured that no significant changes in the vision-related and/or systemic functional status of the subjects would take place. In fact, solid test-retest reliability was indicated by the high values of the intraclass correlation coefficients.

Regarding the construct validation of the questionnaire, none of the items failed either the convergent or the discriminant tests.

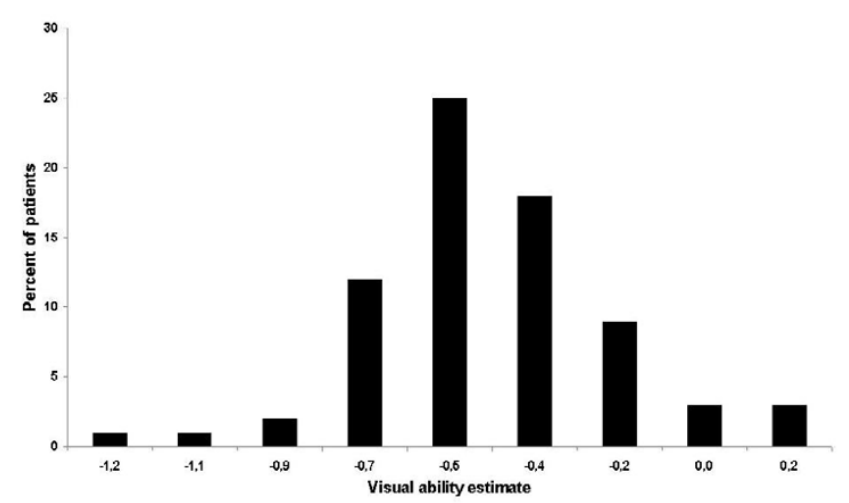

Figure 3

Distribution of visual ability measures.
Strong correlations were detected between visual acuity of the subjects and the "general vision", "distant activities" and "near activities" subscales suggesting that the corresponding subscales were actually associated with central vision. Similar correlations between visual acuity and NEI-VFQ subscales have been detected by previous investigators during the validation of the instrument in other languages as well $[14,15]$. Moreover, in accordance to the concepts investigated by the corresponding items, the visual fields deficits of glaucoma subjects were associated with "peripheral vision" and "general vision" subscales. In fact, the results of our study regarding the impact of visual fields deficits on VS-QoL are similar to the ones by Ringsdorf and coworkers for the white, non-Hispanic population of their study [34].

On the other hand, item response analysis revealed potential weaknesses of the questionnaire that should be taken into consideration prior to the interpretation of results. These potential weaknesses are associated with the assumptions of the Rasch model. Among these assumptions are: a) only one variable is measured by the instru-

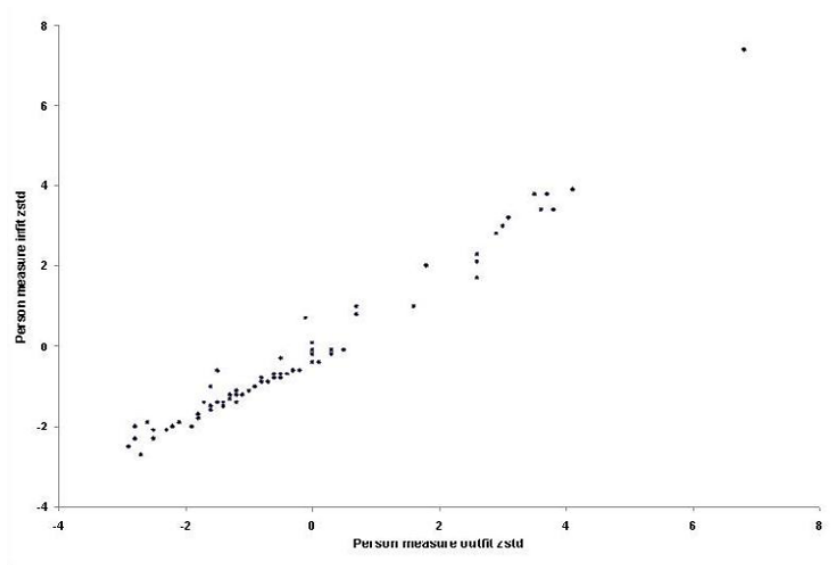

Figure 4

Distribution of the infit and outfit statistics for the estimates of visual ability. 
ment, b) subjects' responses to the items depend only on visual ability, c) subjects' responses are probabilistic and conditional on the subjects' visual ability required to perform that activity with ease, d) the odds of performing an activity with ease increase monotonically with the difference between the subject's ability and the ability required to perform the activity with ease. The results of the study indicate that the items requiring agreement ratings presented low precision in the estimation of the latent variable, contrary to the items requiring difficulty ratings, which presented higher precision. However, other investigators have presented similar results on their evaluation of the performance of certain NEI-VFQ items [35]. This suggests potential inherent validity issues related to the original instrument, rather than its translation and adaptation to the Greek language. Nonetheless, the important limitations of the scale detected with Rasch analysis may make it unsuitable for use.

Besides the aforementioned potential weakness of the instrument, certain limitations of our study may have to be considered. The translation process presented minor deviations from international recommendations. However, the research team is confident that these minor deviations had no actual impact on the translated outcome. On the other hand, the results are valid for the corresponding conditions of the patient groups and for the selfadministered version of the instrument. Thus, prior to the usage of the instrument as a reliable index of VS-QoL in Greek patients with other diseases (i.e. diabetic retinopathy), further validation may be necessary in an appropriate sample of patients.

A series of vision-specific QoL studies conducted in homogenous populations have assessed the impact of systemic or ocular diseases on VS-QoL $[1,2,36]$. The outcomes of these studies could potentially modify the overall thinking on chronic disease management, since the patients' subjective perceptions regarding their visual impairment are not always in accordance with objective clinical parameters like the visual acuity or the visual fields. Literature suggests that in selective cases, non-clinical parameters such as educational background, financial state, or awareness regarding the disease have greater impact on the quality of life than objective clinical indices [37].

The majority of VS-QoL instruments attempt to quantify QoL by evaluating potential difficulties during a wide range of daily activities. It becomes obvious that the performance of QoL instruments (i.e. reliable assessment of subjective difficulty) depends heavily on the proper adaptation of the items to the cultural characteristics of the population studied, especially if the instrument was orig- inally developed for a population with a different cultural background.

\section{Conclusion}

Our results indicate that according to traditional validation methods, the Greek version of the NEI-VFQ 25 is a valid and reliable instrument for the assessment of VSQoL in native populations. These findings are in agreement with the majority of previous research that translated and validated the instrument in series of ophthalmic patients by means of traditional validation methods, thus providing the theoretical framework for numerous VSQoL studies. On the other hand, Rasch analysis revealed important misfits to the model, mainly of the "agreement" items, suggesting that the results of the corresponding subscales have to be interpreted with extreme caution. The significant limitations detected with Rasch analysis may render the instrument unsuitable for use. Further research is warranted for the re-evaluation of the performance of NEI-VFQ 25 as a VS-QoL instrument.

\section{Competing interests}

The author(s) declare that they have no competing interests.

\section{Authors' contributions}

GL conceived of the study and participated in its design and coordination. He also drafted the manuscript.

AK was involved in drafting the manuscript and revising it critically.

MP participated in data acquisition and study coordination.

MF performed the statistical analysis.

TT was involved in data acquisition and interpretation.

ET contributed to the study design and reviewed the manuscript critically.

DC coordinated the study and revised the manuscript.

All authors read and approved the final manuscript. 


\section{Additional material}

\section{Additional file 1}

Multitrait-multimethod matrix. Matrix of correlation for the assessment of construct validity of sets of measures. Instead of " 1 " along the diagonal (as in a typical correlation matrix) we have substituted an estimate of the test-retest reliability of each measure.

Click here for file

[http://www.biomedcentral.com/content/supplementary/14712415-8-4-S1.xls]

\section{References}

I. Nutheti R, Shamanna BR, Nirmalan PK, Keeffe JE, Krishnaiah S, Rao GN, Thomas R: Impact of impaired vision and eye disease on quality of life in Adhara Pradesh. Invest Ophthalmol Vis Sci 2006, 47:4742-4748.

2. Mitchell J, Bradley C: Quality of life in age related macular degeneration: a review of the literature. Health Qual Life Outcomes 2006, $21: 97$.

3. Jacobs JM, Hammerman-Rozenberg R, Maaravi Y, Cohen A, Stessman $\mathrm{J}$ : The impact of visual impairment on health, function and mortality. Aging Clin Exp Res 2005, 4:281-286.

4. Chabert S, Velikay-Parel $M$, Zehetmayer $M$ : Influence of uveal melanoma therapy on patients' quality of life: a psychological study. Acta Ophthalmol Scand 2004, 82:25-31.

5. Tripop S, Pratheepawanit N, Asawaphureekorn S, Anutangkoon W, Inthayung S: Health related quality of life instruments for glaucoma: a comprehensive review. I Med Assoc Thai 2005, 88(Suppl 9):SI55-I62.

6. Bergner M, Bobbitt RA, Carter WB, Gilson BS: The Sickness impact profile: development and final revision of a health status measure. Med Care 1981, 19:787-805.

7. Mangione CM, Phillips RS, Seddon JM, Lawrence MG, Cook EF, Dailey $\mathrm{R}$, Goldman L: Development of the "Activities of daily vision scale": a measure of functional status. Med Care 1992, 30:1111-1116.

8. Ware JE, Sherbourne CD: The MOS 36-item short-form health survey: I. Conceptual framework and item selection. Med Care 1992, 31:247-263.

9. Anagnostopoulos F, Niakas D, Pappa E: Construct validation of the Greek SF-36 Health Survey. Qual Life Res 2005, | 4:1959-1965.

10. Mangione CM, Lee PP, Gutierrez PR, Spritzer K, Berry S, Hays RD, National Eye Institute Visual Function Questionnaire Field Test Investigators: Development of the 25-item National Eye Institute visual function questionnaire. Arch Ophthalmol 200I, I 19:1050-1058.

II. Mangione CM, Berry S, Spritzer K: Identifying the content area for the 5 I-item National Eye Institute Visual Function Questionnaire: results from focus groups with visually impaired persons. Arch Ophthalmol 1998, 16:227-233.

12. Nordmann JP, Viala M, Sullivan K, Arnould B, Berdeaux G: Psychometric Validation of the National Eye Institute Visual Function Questionnaire - 25 (NEI VFQ-25) French version: in a population of patients treated for ocular hypertension and glaucoma. Pharmacoeconomics 2004, 22:197-206.

13. Suzukamo Y, Oshika T, Yuzawa M, Tokuda Y, Tomidokoro A, Oki K, Mangione CM, Green J, Fukuhara S: Psychometric properties of the 25-item National Eye Institute Visual Function Questionnaire (NEI VFQ-25), Japanese version. Health Qual Life Outcomes 2005, 3:65.

14. Rossi GC, Milano G, Tinelli C: The Italian version of the 25-item National Eye Institute Visual Function Questionnaire: translation, validity, and reliability. J Glaucoma 2003, 3:2 I 3-220.

15. Toprak AB, Eser E, Guler C: Cross-validation of the Turkish version of the 25-item National Eye Institute Visual Functioning Questionnaire (NEI-VFQ 25). Ophthalmic Epidemiol 2005, I 2:259-269.
16. Jampel HD, Schwartz A, Pollack I, Abrams D, Weiss H, Miller R: Glaucoma patients' assessment of their visual function and quality of life. J Glaucoma 2002, I I:I54- I63.

17. Cahill MT, Banks AD, Stinnett SS, Toth CA: Vision-related quality of life in patients with bilateral severe age-related macular degeneration. Ophthalmology 2005, I I 2(I): I52- I 58.

18. Cusick M, SanGiovanni JP, Chew EY, Csaky KG, Hall-Shimel K, Reed GF, Caruso RC, Ferris FL: Central visual function and the NEIVFQ-25 near and distance activities subscale scores in people with type I and 2 diabetes. Am J Ophthalmol 2005, I39(6): I042-1050.

19. Nichols KK, Mitchell GL, Zadnik K: Performance and repeatability of the NEI-VFQ-25 in patients with dry eye. Cornea 2002, 2 I (6):578-583.

20. Hall TA, McGwin G, Searcey K, Xie A, Hupp SL, Owsley C, Kline LB: Health-related quality of life and psychosocial characteristics of patients with benign essential blepharospasm. Arch Ophthalmol 2006, I24(I): II6-II9.

21. Burstedt MS, Monestam E, Sandgren O: Associations between specific measures of vision and vision-related quality of life in patients with bothnia dystrophy, a defined type of retinitis pigmentosa. Retina 2005, 25(3):317-23.

22. Cahill MT, Stinnett SS, Banks AD, Freedman SF, Toth CA: Quality of life after macular translocation with $\mathbf{3 6 0}$ degrees peripheral retinectomy for age-related macular degeneration. Ophthalmology 2005, I | 2: |44-|5|.

23. Biousse V, Tusa RJ, Russell B, Azran MS, Das V, Schubert MS, Ward $M$, Newman NJ: The use of contact lenses to treat visually symptomatic congenital nystagmus. J Neurol Neurosurg Psychiatry 2004, 75:3 14-316.

24. Stelmack JA, Stelmack TR, Massof RW: Measuring low-vision rehabilitation outcomes with the NEI VFQ-25. Invest Ophthal$\mathrm{mol}$ Vis Sci 2002, 43:2859-2868.

25. Laboratory of Experimental Ophthalmology of Aristotle University, Thessaloniki, Greece 2000 [http://www.rand.org/ health/surveys tools/vfa]. [Accessed 26 Feb 2007]

26. Vitali C, Bombardieri S, Moutsopoulos HM, Coll J, Gerli R, Hatron PY, Kater L, Konttinen YT, Manthorpe R, Meyer O, Mosca M, Ostuni P, Pellerito RA, Pennec Y, Porter SR, Richards A, Sauvezie B, Schiødt M, Sciuto M, Shoenfeld Y, Skopouli FN, Smolen JS, Soromenho F, Tishler M, Tausic M, van de Merwe JP, Yeoman CM, Wattiaux MJ: Assessment of the European classification criteria for Sjogren's syndrome in a series of clinically defined cases: results of a prospective multicentre study. The European Study Group on Diagnostic Criteria for Sjogren's Syndrome. Ann Rheum Dis 1996, 55:116-121.

27. Cronbach LJ: Coefficient alpha and the internal structure of tests. Psychometrika 195I, 16:297-334.

28. Campbell DT, Fiske DW: Convergent and discriminant validation by the multitrait-multimethod matrix. Psychol Bull 1959, 56:8I-105.

29. Andersen EB: A goodness of fit for the Rasch model. Psychometrica 1973, 38:123-140.

30. Andrich D: A rating formulation for ordered response categories. Psychometrica 1978, 43:561-573.

3I. Lamoureux EL, Ferraro JG, Pallant JF, Pesudovs K, Rees G, Keeffe JE: Are standard instruments valid for the assessment of quality of life and symptoms in glaucoma? Optom Vis Sci 2007, 84:789-96.

32. Massof RW, Lohrasb $A:$ What do different visual function questionnaires measure? Ophthalm Epidem 2007, I4:198-204.

33. Lamoureux EL, Hooper CY, Lim L, Pallant JF, Hunt N, Keeffe JE, Guymer RH: Impact of cataract surgery on quality of life in patients with early age-related macular degeneration. Optom Vis Sci 2007, 84:683-688.

34. Ringsdorf L, McGwin G, Owsley C: Visual fields defects and vision-specific health-related quality of life in African Americans and Whites with glaucoma. J Glaucoma 2006, 5:4|4-4I8.

35. Massof RW, Fletcher DC: Evaluation of the NEI visual function questionnaire as an interval measure of visual ability in low vision. Vision Research 200I, 41:397-4I3.

36. Hirneiss C, Rombold F, Kampik A, Neubauer AS: Visual quality of life after vitreoretinal surgery for epiretinal membranes. Ophthalmologe 2006, 2:109-113. [In German]

37. Baker RS, Bazargan M, Calderon JL, Hays RD: Psychometric performance of the National Eye Institute visual function ques- 
tionnaire in Latinos and non-Latinos. Ophthalmology 2006, I 13:1363-137|.

\section{Pre-publication history}

The pre-publication history for this paper can be accessed here:

http://www.biomedcentral.com/1471-2415/8/4/prepub

Publish with Bio Med Central and every scientist can read your work free of charge

"BioMed Central will be the most significant development for disseminating the results of biomedical research in our lifetime. " Sir Paul Nurse, Cancer Research UK

Your research papers will be:

- available free of charge to the entire biomedical community

- peer reviewed and published immediately upon acceptance

- cited in PubMed and archived on PubMed Central

- yours - you keep the copyright 